\title{
Earthquakes, Cancer and Cultures of Fear: qualifying as a Skills for Life teacher in an uncertain economic climate
}

\author{
Matt O'Leary and Rob Smith \\ School of Education, University of Wolverhampton, Walsall, UK, \\ University of Wolverhampton, School of Education, Walsall Campus, Gorway Road, \\ Walsall, WS1 3BD, UK. Email: moleary@wlv.ac.uk
}

\begin{abstract}
The Skills for Life (SfL) initiative followed the Moser Report (1999) and incarnated a Third Way agenda that sought to address England's perceived adult skills deficit. SfL marked a large investment in adult education but also a distinct shift to a more focused, instrumentalist role for Further Education (FE) in England. A new structure of teacher standards and qualifications underpinned this development with its own, newly devised and matriculated knowledge base. Teachers emerged from these new programmes with subject specialisms in Literacy, Numeracy and English for Speakers of Other Languages (ESOL). The landscape that these 'new professionals' have entered is one that suggests the autonomy of colleges within a competitive market, but this disguises a funding methodology that facilitates ongoing centralised policy intervention. In the last two years policy makers have used this funding methodology to shift monies decisively towards 14-19 provision and away from adult education. This article draws on qualitative data from a study into the experiences of pre and in-service SfL teachers in the final stages of qualification. The data explores the impact of these latest movements in the FE market on these student teachers who are qualifying in some of the newest subjects in FE.
\end{abstract}

Keywords: marketisation, managerialism, professionalism, Further Education

\section{Skills for Life: Marketised Policy Context}

The Skills for Life (SfL) policy initiative sits within a Further Education (FE) terrain that has been organised through a complex set of inter-relationships between colleges, government, funding agencies, market regulators and students. These relationships involve the interplay of 'market information', college statistical data and funding and the policyscape in which they are played out can best be described as 'marketised'. 
FE marketisation is one aspect of the policy of centralisation that has unfolded over the last two decades and has involved a steady decrease in the powers and machinery of local government. This was part of wider policy movements that extended to other parts of the education system. In the context of schools, Bache describes the change in education policy as a movement to 'multi-level governance' (Bache, 2003, p. 301) but concludes that 'in terms of financial resources, central government policies ... undermined the role of localities and strengthened central control' (p. 313). The FE context experienced the same changes but with significant differences.

The backdrop of structurally altered relationships between the state and FE providers had its counterpart at the micro-level in a shift in the work and working conditions of FE teachers, changes that the literature characterises through a series of analytical labels of "deprofessionalisation" (e.g. Yarrow \& Esland, 1998) and “proletarianisation" (Randle and Brady, 1997); teachers' identities were described as "in flux" (Stronach et al, 2002); FE teachers were challenged within the newly business-orientated culture to "strategically comply" (Shain \& Gleeson, 1999) or to adopt privileged "entrepreneurial" models of identity (Sachs, 2001). The ongoing debate around the significance of FE teachers' status is indicative of contention but, we would argue, it also underscores that the incorporation of colleges brought about a set of power relationships that fundamentally altered the forces and cultures that shape teachers' identities within the sector. 
But what exactly are the substantive features of the marketisation of the FE sector that distinguish it from other educational 'markets'? The FE market contrasts with the school marketisation model, brought about by the Education Reform Act (1989), in several key ways. Chief amongst these is a contrasting relationship between the curriculum and the funding of individual providers. School funding is based on a per capita payment model with additional funds attracted by formulae relating to 'Additional Educational Need' and free school meals take-up (Bache, 2003, p. 310). Under this model, schools are incentivised to grow - the size of the school being indicative of its popularity - which is again linked to achievement levels, inspection grades and its position in a league table of schools. The curriculum backdrop for this market model is comparatively stable. While the emphases might change (for example, through the introduction of synthetic phonics or a daily Literacy hour in Primary schools or through specialisation in secondary schools), the National Curriculum maintains a platform with some continuity. Furthermore, state schools enjoy a basic stability that links to catchment area.

The funding for colleges made a break from this approach in 1993 after the 1992 Further and Higher Education Act (HMSO, 1992). Instead of per capita, college funding has since then been organised around the concept of unit totals. The original model paid colleges for on Entry units (recruitment), on course units (retention) and completion (achievement). This was felt not to emphasise achievement enough so the methodology was changed to privilege that (e.g. Lee, 2009). This means that 
colleges are funded according to 'success' rates. In other words, FE funding is based on the current formula: retention $\mathrm{x}$ achievement $=$ funding allowance. Only courses resulting in a recognised qualification are funded. In addition, a baseline tariff details how much each course is worth. Courses are made more or less financially attractive for colleges to deliver according to government policy priorities. In the case of incentivised courses, these receive higher levels of funding (as much as $40 \%$ per annum) or more, though the variation in incentives of this kind can change annually. In this regard, FE colleges experience shifting curricula and this instability impacts on staffing annually in a way that doesn't affect schools.

As previously suggested, a college's curriculum can change on a yearly basis. This is because colleges need to be responsive to multiple variables in terms of the provision offered. Firstly there are the ongoing policy developments relating to new qualifications - some of which might have whole college implications (e.g. Functional Skills or the 'flagship' - and now less significant - 14-19 Diploma). Then there are the annual funding methodology adjustments (set centrally by BIS 'partner organisation the Skills Funding Agency) - requiring further engagement or withdrawal from some curriculum areas according to potential financial return. Finally, there are the fluctuations in recruitment to the different courses on offer. If insufficient students are recruited at the appropriate level then those courses are vulnerable to closure, which can result in job losses for teaching staff. This means that a key feature of FE marketisation is that there is reduced job security. 
Redundancies are relatively common. For example, in 2009 one of the four Birmingham colleges featured in this study sought 76 redundancies (UCU, 2009), while in 2010, another of the four proposed 100 redundancies (BBC, 2010).

One major cultural development in the FE sector that has been identified as a response to marketisation is that of managerialism (Randle \& Brady, 1997). Managerialism as a means of mediating working cultures and managing college has spread across FE as public 'accountability' for resources has become politicised (Gleeson \& James, 2007). It is also related to the commodification of education as policy makers require positivist data and organise funding around outcome data.

Closely linked to managerialism is the notion of 'performativity' (e.g. Ball, 2003), which can be best described as a cultural response to managerialist practices. In FE it is a response on the part of individuals but also within colleges that have internalised market practices to competition and the potentially punitive financial nature of accountability. As such performativity has become an effect of managerialism as teachers adopt practices that present their work 'outputs' in a favourable way. In some cases this even extends to the fabrication of data or statistics and can be seen as one effect of the importation of cultures of entrepreneurialism into education, as others have argued (e.g. The Literacy Study group, 2010; Perryman, 2009). 


\section{'Skills' and SfL}

Into this context the SfL initiative was launched, setting targets to raise adult achievement levels in Literacy, Numeracy and English for Speakers of other Languages (ESOL). It aimed to lift 'some 3.5 million adults out of low levels of literacy by 2010' (DfES, 1999) and recommended expenditure of $£ 1.1$ billion. Qualifications were introduced in order to establish subject specialist knowledge bases for teachers of these subjects. SfL also put in place a suite of prescribed 'curricula' (in fact, a matrix for identifying numeracy, language and literacy skills at different levels) for these, the newest 'professionals' in the FE sector.

The policy narrative underpinning the SfL initiative centres on 'skills' and employment and is grounded in economic arguments. Indeed, it can be viewed as an aspect of a range of policy interventions seeking to secure the skills supply in a specific area of need (Keep, 2006). Critiquing Skills for Life (DfEE, 2001) Hodgson et al (2007) contend that the document problematizes SfL students implying that they are 'a drain on the economy and society' (p. 5). Hamilton and Hillier (2006) detail how the policy also enshrined the Third Way agenda of combining economic prosperity with social cohesion.

The entrenchment of this policy discourse and its links to global economic perspectives are emphasised by Keep (2008) who states: 
(The) linking of skills policies to relative economic competitiveness and thence to national survival represents a persistent tradition on the part of some policy makers in seeking to cast discussion of relative performance on skills as part of a hegemonic discourse that will ... prioritise this area of policy over others. (p. 3)

That the discourse still has currency is perhaps best exemplified by the SFA Annual Report 2011:

Skills are integral to accelerating economic prosperity; creating competitive business advantage in a challenging global environment and empowering individuals to change their own lives for the better. (SFA 2011, p. 2)

SfL was a policy initiative borne of this hegemonic skills discourse that created new and distinct teaching posts and new, accredited subject specialisms. However, a fundamental distinction to emerge in time was that SfL qualifications belonged in a 'skills' stable, compartmentalised from 'academic' subjects. One area that the study discussed in this paper sought to illuminate was just how this position of SfL subjects within the market of FE provision might impact on SfL teachers in the longer term.

\section{Recent Funding Changes in SfL}

In the context of this study, over the last two years there have been significant changes in the funding methodology as it relates to SfL. In 2009, The Skills Investment Strategy (BIS, 2009) proposed a reduction in the cost weighting attached to Literacy and ESOL provision from 1.4 to 1.2. This was followed by the Skills for Sustainable Growth Strategy (BIS, 2010a) that heralded a further reduction in funding from 1.2 to 1 , effectively removing policy prioritisation of Literacy and 
ESOL (Numeracy was unaffected in both adjustments). ESOL, it was further announced, was no longer to be fully funded and would only be free for students on 'active' (e.g. Job Seekers' Allowance) as opposed to 'passive' benefits.

The insights emanating from students and providers in the region during the academic year 2010-11 were that ESOL was vulnerable as a subject area and that redundancies were likely to be widespread in SfL subjects as a whole. Another factor that strengthened feelings of despondency amongst the (particularly in-service) participants was the ongoing introduction of Functional Skills in colleges. The Literacy and Numeracy aspects of these qualifications, supporting vocational qualifications for young people as well as being freestanding, are viewed as the long term replacement of the adult Literacy and Numeracy qualifications. To that extent, there is cognisance that the SfL initiative is 'old policy' and that the focus has moved on.

Our study then was focused on a specific FE policy moment and aimed to chart its impact on a cohort of qualifying SfL teachers. It aimed to foreground the thoughts and feelings of new entrants to the profession after almost two decades of marketisation. 


\section{Methodology}

This study aimed to explore the impact of policy announcements and funding changes on student SfL teachers while they were studying. The sample for the study drew on students who were either already working in the sector (in-service) or were on teaching placements (pre-service) in colleges and providers in the West Midlands. Although it was confined to those teaching SfL provision, the profile of participants was broadly representative of the 'heterogeneity' of those teaching in FE (Huddleston \& Unwin, 2007). It encompassed both pre-service and in-service teachers. In the case of the latter, these were teachers who were mainly employed on a part-time/hourly basis in local colleges and adult education providers, although it also included those working in training providers who were invariably employed on full-time or full-time equivalent contracts. Regardless of their employment situation, all these in-service teachers were working towards their teaching qualification on a part-time basis over a two-year period of study. They were following the integrated route of the Diploma in Teaching in the Lifelong Learning Sector (DTLLS) for teachers of ESOL, Literacy or Numeracy, which was a 'two-in-one' programme that incorporated their subject specialist qualification as well as the 'generic' teaching qualification required of all those responsible for a 'full teaching role' in the sector (LLUK, 2006). Many of them had completed preliminary programmes of study such as the PTLLS (Preparing to Teach in the Lifelong Learning Sector) and/or CTLLS (Certificate to Teach in the Lifelong Learning Sector) prior to starting the course and all had at least some experience of teaching. From these participants a culturally 
absorbed perspective emerged - having insights not just into the decisions being made and their impact but in some cases into the reasons and justifications for such decisions.

The second group of pre-service participants offered a different set of perspectives. Many of them were on second careers. Typically they were aged 30 and above, and had substantial experience in work other than teaching. For example, the sample included an ex-children and families solicitor, a community police officer and a deaf signer. In short, there were 26 respondents in total. The sample included nine different colleges, two Adult Education services and two training providers.

The research data this paper draws on was collected between February and June 2011. The participants were students on pre-service and in-service teacher education programmes at the University of Wolverhampton in the academic year 2010-2011. Developed through the critical reflective practice at the heart of the integrated skills DTLLS qualifications, participants' reflective journal entries were used as the main data collection tool.

The issue of the impact of funding changes had already surfaced in students' journal entries spontaneously prior to the start of the study, which highlighted how it had begun to encroach on their lives as student teachers. As course tutors we were keen to develop a greater understanding of the repercussions of the proposed funding 
changes and thus decided to draw up a list of prompts, which was sent to a group of approximately 30 in-service students and 30 pre-service students:

- What has been the impact of policy (and funding) changes in the departments you are working in? Can you describe the mood/atmosphere?

-What do you see as the impact of these changes in the coming year in your subject/department?

- What has been the impact of these issues on you and your development as a SFL teacher?

The aims were twofold: first to generate a discursive sphere of engagement that united the participants in the common aim of exploring the current context and their perceptions of it; second, to give voice to a group of new entrants to the profession as SfL practitioners.

Initially, the two data sets (i.e. pre-service and in-service) were analysed separately by both researchers. As a means of strengthening the internal validity of the research, the data sets were then exchanged and the initial codes/categories drawn up by each researcher were compared alongside the interpretations of each other. Our methodology was neither hypothesis-testing nor hypothesis-generating in the strict sense of a grounded theory approach (Glaser \& Strauss, 1967), but more a mixture of the two. Although the categories of analysis emerged from the data and 
as such were not pre-determined, they were informed by the theory and relevant literature that we drew on. Thus in Bourdieusian terms, the research process was 'relational' i.e. practice was informed by theory and vice versa.

Equally, both researchers had previously researched in FE contexts and this experience along with the experience gleaned from long term observations across a number of years in the sector informed the perspectives brought to bear on the data. In the context of qualitative research, Creswell (2003, p. 182) argues:

This means that the researcher makes an interpretation of data ... It also means that the researcher filters the data through a personal lens that is situated in a specific socio-political and historical moment.

Thus, for example, theories of managerialism and performativity helped to situate the research focus in a specific socio-political and historical context, whilst also allowing us to draw on established concepts and terminology from cognate studies to interpret and make sense of some of the narratives of the study's participants. Respondents were sent the codes/categories and a summary of the main themes and issues relating to them via email. They were asked to comment. The email correspondence stressed the importance of accurately capturing their voices and thus they were encouraged to offer challenging or contradictory interpretations if they disagreed with the coding. A minority of participants responded, all of whom agreed with the coding. Although some researchers have argued that this type of validation is not wholly effective as a means of testing out ideas or theories and 
establishing the quality of qualitative inquiry (Gorard \& Taylor, 2004), others see it as an important strategy in reducing the occurrence of inaccurate and/or unrepresentative interpretations of data (e.g. Cohen, Manion \& Morrison, 2011).

\section{Discussion of Findings}

The analysis we present here focuses on the two most significant themes arising from the data. We have chosen to start by looking at the comments participants made that related to the emotional reactions of staff to the funding crisis. One reason for this is that we aim to proceed using an enhanced model of critical reflection that suggests a foregrounding of the affective impact of the funding cuts is necessary.

The data provided by the two groups of participants have distinct features. While pre-service participants view the terrain with fresh eyes, not yet conditioned to prevailing sectoral cultures, the in-service participants provide detail that is made possible by their position as 'insiders' insomuch as they are able to read and interpret information that might be inaccessible to the pre-service students. The data not only provided us with participants' feelings and commentaries on the changes, but also helped to elucidate the ways in which policy decisions within the FE quasimarket were being mediated and implemented by providers. 


\section{Cultures of fear}

One of the first patterns to emerge from the participants' critical reflection concerned the emotional effects of the 'climate of austerity' on their work and that of their colleagues. These effects were part of a wider malaise across the sample which we refer to as 'cultures of fear'. Kay, a part-time ESOL teacher commented:

The financial crisis has hit my workplace with the dramatic force of a Japanese earthquake and the aftershock continues to quake within the walls... At the staff training day rumour spread of the extent of forthcoming redundancies. The atmosphere was one of disbelief and fear among staff who were aware their jobs were on the line. In particular, shock at the news of the closure of the Vocational Access course... The beginning of autumn term 2010 was hectic in the ESOL department as classes were larger, lessons were shorter and evening classes were closed.

Kay's comparison of the funding cuts to an unexpected natural disaster is notable.

The immediate affective impact of the changes to funding is communicated powerfully. Kay mentioned that specific adult provision is earmarked for closure. This evidences the impact of policy steers and funding (dis)incentives that make some provision less attractive financially. We would argue that the year on year incentivisation of different areas of provision in response to policy development is a feature of FE marketisation. The FE sector is organised in such a way that colleges must review the courses they offer on an annual basis as the value of provision may go up as well as down - even when it comes to comparatively 'new' courses and subject areas. Kay also remarked how she had 'lost (her) class to a full time member of staff'. This illustrates how part-time, casualised teachers without permanent contracts are the most vulnerable when colleges face budget cuts - a particularly significant finding when we remember that part-time work is a traditional starting 
point for many newly qualified teachers in the sector or what has been commonly referred to as the 'long interview'(Gleeson et al., 2005).

While efficiency is clearly increased (more students, shorter classes etc.), the closure of specific courses (e.g. the vocational Access course) indicates that in straitened times, efficiencies are not simply an issue of 'productivity' but impact on the FE curriculum resulting in closure of some curriculum areas. This contrasts powerfully with the curriculum on offer in state schools. In terms of the impact on teaching staff, this is a good example of what we see as the impact of marketisation. Kay perceives that provision that has been secure can suddenly become vulnerable in institutional terms, irrespective of any action on the part of teaching staff.

In contrast to Kay's rather gloomy picture, Ellie, a part-time literacy teacher working for two different organisations, viewed the uncertainty of part-time or sessional contracts in a more positive light:

Organisations like the adult education service I work for can award sessional contracts as and when the work is available. Although being on sessional contracts means things can feel rather uncertain, in reality it allows greater flexibility. It means that I can work for several employers and spread the risk in a way I couldn't do with one part-time contract ... I may be being over optimistic but at the moment things don't feel too bad for me. I just need to 'go with the flow' and see where it takes me. In my situation I can cope with the uncertainties, but it must be really hard and stressful for those with families and large mortgages.

It is worth highlighting that Ellie's 'optimistic' viewpoint of the current climate was largely a lone voice among the in-service participants, although as she qualified in the final sentence, her personal situation enabled her to 'cope with the uncertainties' 
unlike 'those with families and large mortgages'. Ellie's comments were noteworthy not simply because they allowed us to check the meaning of 'outliers' (Miles \& Huberman, 1994) or those exceptions that did not fit the overall pattern of the findings, but they also offered an alternative vision of a 'preferred professional' in a market-driven FE sector. In other words, this 'preferred professional' was someone who would be willing to 'go with the flow' by embracing the uncertainty of the sector and 'spread[ing] the risk' by working for several employers. This acknowledgement of ongoing job insecurity in the FE sector is another distinguishing feature of FE marketisation. Yet this 'risk' was something that many tutors were uncomfortable with as highlighted in the comments of Alan, a full-time numeracy tutor working in a training provider:

The atmosphere within the department is abysmal, to say the least! Unless you have been through this sort of situation, I do not think you can truly understand the effect on you of seeing not just colleagues, but in many instances good friends, so emotionally low and frightened ... One other disturbing effect of the situation has been on colleagues' attitude to their vocation. Although they much prefer teaching adults, two, experienced, excellent tutors I know are looking to return to teaching in primary school, because they have become convinced that it is a more secure career option.

Alan's account of the impact of the funding cuts in his workplace pointed to a less optimistic interpretation than that of Ellie's above. Notable in Alan's account were the tangible effects on him and his colleagues' notions of self. Besides, in the reference to his two colleagues that were 'looking to return to teaching in primary school [because] it is a more secure career option', Alan's account serves not only to reinforce earlier discussion concerning job insecurity as a feature of the 
marketisation of FE, but also to provide a contextualised example of how being a teacher in the schools' sector is perceived as a more stable career.

Another of the in-service participants, Sue, a freelance artist, was employed as a part-time ESOL tutor at a local adult education service. When the news of job cuts first surfaced in her workplace she was summoned to attend a meeting hosted by representatives of senior management:

\begin{abstract}
We were given (by the Management Information Systems manager) the analogy of having cancer and asked to think about what percentage of survival rate we would choose, this was apparently to help us understand the survival rate of our service! .... Faces around the room dropped, some with horror at the analogy used, some with despair of the prospect of having no jobs come the start of the next academic year. So morale slumped right from the start of the new term.
\end{abstract}

That such a comparison should be made between cancer and the likelihood of future employment for staff was shocking itself, but this conceptualisation also reflected a wider managerialist and marketised response to the financial crisis and impending funding cuts in some workplaces. In other words, the link to marketisation was reflected in the prioritisation of the financial health of the institution above everything else here. Since incorporation, FE colleges have had to develop the ability to expand and contract according to market conditions - particularly due to changes in the funding methodology. Secondary to this is any consideration of students' needs or the maintenance of secure employment for staff. This oncological metaphor is instructive in the sense that it exposes the workings of technical rationality (Habermas, 1986); the imbalance between input and output is remediable if the 
appropriate technical steps are taken. Tellingly, any sociological or moral considerations are disregarded and deemed to be outside the scope of any technical response to the issue. The reduction of 'survival' to a crude percentage is symptomatic of how little regard is given to the effects on the emotional lives of staff in such difficult circumstances.

In an extension of the previous excerpt, Sue expressed her feelings on how the news of the impending cuts impacted on her as an individual and a student teacher:

The effects of this, on me personally, have been very negative... The idea that there will be no work for me as an ESOL tutor come the next academic year has made me lose all motivation with regards to the assignments and the course itself ... it's made my efforts feel pointless and unworthy. I've felt that the qualification that I'm working towards will have no value.

A recurring theme in the data that encapsulated this 'culture of fear' was the growing uncertainty and insecurity among those working in SfL provision regarding future employment prospects, which resulted in some questioning the legitimacy or 'value' of the notion of the newly qualified FE professional as alluded to by Sue. It would appear that there were tensions between the aims that had underpinned the original rationale for the creation of these new qualifications and the longevity of their market value. Whilst they were designed to (re)professionalise the FE workforce and establish an element of parity between them and their school counterparts, the 'market-tested' (Gleeson et al., 2005) nature of the sector appears to have militated against any such parity and stability for FE tutors. We would argue 
that this suggests an incompatibility between establishing notions of professionalism and the uncertainty of a marketised sector.

Many of the participants' narratives suggested that being recognised and certified as a professional was of limited currency given the insecurity of SfL posts. For example, in the following excerpt, Magdalena, who like Sue was a part-time ESOL tutor, talked about how the uncertainty of future employment in the sector was a significant factor in a colleague's decision to return to his previous career and was likely to present her with a similar dilemma upon completion of the programme:

My colleague, who completed his Cert Ed last year, has decided to return to his previous career in IT as he simply cannot afford to stay in the FE sector due to the uncertainty of cancelled classes/less hours. I, too, am now faced with having to make a decision to stay in my role as a classroom assistant in a primary school as this is permanent with full-time hours or risk moving into the unpredictable world of part-time FE teaching.

Like Magdalena and her colleague, many of the in-service participants suggested that they were considering returning to their previous professions on the basis that it offered more financial security. The climate of 'unpredictability' surrounding the employment prospects of these newly qualified tutors was exacerbated by the fierce competition for jobs that was already starting to emerge between departments and tutors during the course of the research. These thoughts were echoed in the words of Leanne, a numeracy tutor working full-time for a training provider:

I feel that my progression through my university course with my current employer will bear no fruit... (F)unding that is coming through is more aimed at Apprenticeships and Work Based Qualifications. The reality of this for me means that I will return to assessing rather than teaching. I don't see this as a negative as this is the area that I originally qualified in and I do 
love the job. I do, however, feel that a lot of hard work and effort that has been put into my 2 year course could be wasted.

Although Leanne was not faced with the same dilemmas as Magdalena or Sue regarding the security of her employment, it was interesting to note how this 'security', a theme that also surfaced in Alan's contribution, was not seen as a reward or recognition of her impending certification and development as a numeracy tutor, but was based on a return to her original role as an assessor prior to her DTLLS programme. Paradoxically, it was her lower level qualification as an assessor that would ensure her continued employment. This serves to reinforce previous comments regarding the value of this national qualification for SfL tutors.

Many of the in-service tutors were employed on a part-time basis. They reported that in the current climate of cuts, their hours were particularly vulnerable as employers sought to protect the hours of those in full-time or full-time equivalent posts in the first instance. In the case of two colleges, curriculum managers and Heads of School were instructed to make savings on their budgets for part-time hourly paid tutors wherever possible. This resulted in some of the student teachers in their second and final year of the programme being offered teaching hours on a voluntary basis only when, in fact, they had been paid for them the previous year, heralding a return to the casualisation of this group of FE tutors. 
For the Pre-Service participants, a detailed understanding of the FE context was absent. Having a degree and a post-graduate qualification within a SfL subject specialism, they envisaged working in a college with a permanent contract and a full timetable of ESOL, Numeracy or Literacy. Their experience on placement in the academic year 2010-11 gradually brought about an understanding that neither was a given. Many of the pre-service participants, talked about 'uncertainty' and 'fear', but across the sample, students' responses varied. Two examples elucidate how funding cuts intensified internal marketisation. Julie, an ESOL pre-service teacher at a college describes the atmosphere at her placement:

\begin{abstract}
At first there was a vague uncertainty and reluctance to accept the reality of the funding changes. Then as... it became clear that there would be drastic cuts, there were different reactions. Some teachers were resigned to the situation ... Others were very stressed and started looking at alternative jobs and some were really depressed. Since redundancies were announced, the dept. is waiting to see if anyone will go for voluntary redundancy and there is a lot of tension and anger in the air. There is also resentment towards the ESOL dept. from other departments which have to lose more teachers... (I)t feels as though it's every teacher for him/herself.
\end{abstract}

The range of emotions here is striking. Interestingly, a fragmentation of collegial relations is noted as a particular knock-on effect. Conflict is generated between different departments and tutors are forced to become inward-looking and selfinterested. The internalisation of market forces at the level of the institution is a fruitful way of theorising Julie's experience. Lo et al (2005) address the rationality of financial markets focusing in particular on the role of the primary emotions of fear and greed. Fear of loss is a significant shaper of actions amongst investors in the financial markets. Above, we see a version of market fear as the annually designated 
funding outlay destabilises provision, college structures and the careers of teaching staff.

The phenomenon whereby colleges internalise market discipline is seen in other participants' contributions, as Lucy commented:

Some staff have lost hours and some have had to move to another campus whilst others have been pitched against each other in a kind of bidding war just to get enough hours.

The 'bidding war' involves securing potential teaching hours for the coming year in order to escape the managerialist eye. The commodification of FE (noted by commentators such as Ball, 2003; Smith, 2007a \& b) is illustrated here as teachers internalise an individualistic market mentality and compete with each other to assure their own productivity.

One pre-service participant, Claudia, a Literacy teacher, saw the funding changes as: a direct challenge to the values I brought with me to the profession. The changes have made me stop in my tracks to check whether my values will stay intact if I continue on this journey under the likes of our current govt. They have left me feeling unsure about the difference I can make to communities. The changes have made me more critical of the system and slightly irritated that the state interest will continue eroding away at community and social cohesion.

Claudia identified State intervention as impacting on her sense of the purpose and meaning of the career she was about to embark on. She interpreted the funding changes as targeting specific sections of society and experienced this as an assault on her values. Using Foucault (Foucault, 1982), this might be characterised as evidence of State involvement in the struggle that constitutes the formation of the subject - in 
this case, that of the SfL teacher. What is notable is that from the outset of her career, Claudia registered a tension between her conceptualisation of self-as-teacher and that affirmed by policy.

\section{Managerialism and performativity}

The second major theme to emerge from the data related to the twin phenomena of managerialism and performativity. From the early 1990s onwards, the culture of new managerialism was to redefine the working traditions of colleges nationwide and impact significantly upon the professional identity of the FE workforce (Ainley \& Bailey, 1997). According to Randle and Brady (1997, p. 125), new managerialism was a 'style of management which emerged in the UK in the early 1980 s and gradually spread throughout the Public Sector'. It essentially comprised a package of management techniques taken from the private sector that were considered successful and as such could subsequently 'be applied as a template for public sector institutions' (op. cit., p. 121) to improve levels of productivity and performance and to make the workforce more accountable. Underpinning such models of management were three notions commonly referred to as the three 'Es': economy, efficiency and effectiveness. Recent research claims that FE 'was (and arguably still is) characterised and perhaps dominated by new managerialism' (James \& Biesta, 2007, p. 9). 
The findings of the study revealed how the SfL funding cuts had given rise to an increase in managerialist strategies aimed at maximising the remaining funding available to providers. In times of financial constraint, providers typically draw upon a repertoire of strategies in order to increase 'efficiency'. Such strategies extended to a restriction on basic resources such as photocopying, the removal of Learning Support Assistants from the neediest students and the merging of departments/schools with increased responsibilities for staff at all levels (i.e. senior, middle management and teaching staff). The most drastic efficiencies reported on were redundancies and restructuring exercises.

For the pre-service students, these cultural factors were for the most part unexpected and alien. Harry describes a departmental meeting:

(T)he manager stated that all SfL courses were running at a deficit - figures quoted were that it cost $£ 90$ per hour to run a class at the college (including on-costs) and that the average funding per student being currently drawn down was $£ 4.50$ per hour and class averages were $13-16 \ldots$. It was stated by the manager that there was "too much provision, with too few learners for too few hours" and to continue in this way was not financially viable. There was talk of immediate action to ensure registers were up to date and that any additional hours (particularly with Functional Skills) were 'captured' using an 'open learning register'... The mood was mainly one of resignation.

The primary impression here is of the 'economisation of consciousness' that FE teachers are subject to. Accountability is a key cultural strand of marketised educational cultures (see, for example, PISA, 2011). We would argue that Harry's account illustrates sectoral marketisation as FE teachers are coerced into feeling responsible for market factors that they feel powerless to influence. Recruitment is one such factor. The contradiction here is that the key factor FE teachers can 
influence, the extent to which they are able to create and sustain meaningful and effective educational relationships with students is viewed within managerialist cultures as of marginal interest as compared to the positivist output statistics that teachers are measured against. As Ball (2003, p. 223) has previously argued in discussing performative cultures, 'beliefs are no longer important - it is output that counts. Beliefs are part of an older, increasingly displaced discourse'.

The performative strategy of creating 'open learning registers' to 'capture' additional hours is an example of low level fabrication that jars against notions of professionalism and the idealism it might be supposed new entrants to the profession might bring. The episode resonates with another study into student teachers in FE that revealed a "managerialist and performative hegemony" (Literacy Study Group, 2010 p. 13). This study concluded that the students' peers within their tutor group had become an effective critical forum for processing what were often perceived to be "extreme, instrumentalist and reductive cultures... the result of sustained policy initiatives that have brought about hegemonised technical rationality" (op. cit., p. 16).

This feeling of personal responsibility for the future viability of classes was similarly echoed in the comments of participants from the in-service group. Magdalena, a part-time ESOL tutor describes a scenario that appeared to be commonplace for her part-time peers: 
I first noticed the impact of changes in policy and funding 4 weeks after the beginning of the courses in September 2010. The Management Team introduced a minimum number of 10 students per class and weekly updates were set up confirming numbers. On the very last day before the half-term break in October, I received a call from my line manager saying that due to the fact that my class size was still only "9" and that I had not succeeded in recruiting any more students, the Management Team had decided to cancel my class.

The repercussions of the cancellation of this class were problematic for Magdalena in more than one way. In addition to losing the income from one of only two classes that she taught for this provider, she was faced with the dilemma of ensuring that she was still able to satisfy the requirements of the teaching practice element of the in-service programme in terms of the length and breadth of her assessed teaching (LLUK, 2006). When she approached her line manager about this concern, she was told that if she could 'find some more students to increase the group size' then there was a 'possibility of re-starting the class'.

From the accounts of both pre- and in-service participants, a common picture was forming which suggested that there was a notion of the 'favoured tutor' or what Sachs (2001, p. 156) has previously referred to as 'designer teachers' recognisable by their 'compliance to policy imperatives and [the ability to] perform at high levels of efficiency and effectiveness' (Ibid.). The following excerpt from Katie, a part-time literacy tutor, allowed her to draw on her insider status to exemplify this:

In the current funding climate there is an expectation of further redundancies and a focus on getting through internal observations and Ofsted inspection. The net effect of these systems is to stifle creativity as tutors become obsessed with crazy details such as writing up aims and objectives at the beginning; adhering to their Lesson Plan and keeping to the timing. It is a painting by numbers approach which ticks the boxes but douses any creative spark which has survived this far. 
As it is still one of the stated aims of policy to use the quasi-market 'to drive up standards' (see BIS, 2010b, p. 8), it is interesting here to note how managerialist approaches and their institutional response, performativity, militate against this - or rather provide only an illusion of improvement. As always in marketised situations, there is an attempt to present information under the 'guise of neutrality' (Ranson, 1992, p. 72). Once marketisation is internalised within a college, then it is in the interests of individual departments to fight their corner and present data in the most favourable light possible. The extract above provides a picture of an educational context in which a culture of fear, deriving from market instability, results in an accreditation outcome i.e. the achievement of performance targets that favour the institution. While this behaviour is seen to be adhering to a formulaic approach pleasing to Ofsted, Katie views it as a distraction. For her, it signals reductive practices that meet 'quality' requirements while leaving stories connected to teaching and learning untold.

\section{Conclusion}

This qualitative research project aimed to explore the impact of funding cuts on qualifying SfL teachers during the course of the 2010-11 academic year. The study sought the views and feelings of student teachers to give a sense of how policy impacts on the work and lives of those in the FE sector. The data revealed widespread cultures of fear with a consequent feeling of disempowerment on the part of teachers. The data also suggested that these cultures of fear were an integral 
rather than accidental aspect of a marketised environment. The study found that the newness and low status of SfL subjects within the FE curriculum in all likelihood did contribute to the relative vulnerability of SfL staff relating to job security and redundancy. For Literacy and ESOL, and to a lesser extent Numeracy, the removal of a policy halo that guaranteed protected status meant that the 'hand of the market' far from being 'invisible' appeared to be actively working to undermine the value and relevance of the SfL teaching qualification that these student teachers were just completing.

The study also affirmed the view that in settings that are regulated by markets, certain identities attract market value; they are less vulnerable and generate feelings of security. Other identities on the other hand, are riskier - those that incorporate substantial experience and the enactment of principles and values that are opposed to perfomative 'box-ticking' exercises, for example. There is a complexity of variables in this. Subjects newly created in response to policy, such as SfL, do not enjoy the status of more established disciplines. However, marketisation introduces unpredictability and strategic institutional decisions can make vulnerable the 'safest' of subjects. The perspectives of the in-service students suggested that the cohort as a whole was entering a career that was likely to involve fragmentary, part-time work spread across multiple sites and drawing on previous careers as a safety net. 
Finally, and more broadly, the study has illustrated how the use of markets as an organising principle in FE has consequences. Efficiency is only one effect. Other equally powerful effects are a homogenising and neutering impact on teaching as commodification takes hold and an increased deployment of performative data as institutions struggle to balance providing genuinely educational experiences with juggling inauthentic and fabricated 'market information'. Markets reorganise through crisis, making fear and instability structural features of provision. Such a fundamental influence cannot but impact on the teachers joining the FE sector and on the education students receive. Keep (2006) contends that governmental regulation of employers to orchestrate skills demand is a no-go policy area and that this has resulted in escalating intervention in skills supply in English education and training. That may be the case, but in our view, the changes in funding to SfL subjects provide a clear example of centralised regulation of demand for SfL teachers. By reducing funding for specific subject areas, government deftly reduces the colleges' need for teaching staff in that subject.

What possible ways forward can be offered? The FE market as it currently operates is a perfect platform for ongoing policy meddling. The funding methodology is a technocratic technology facilitating continuous governmental tweaking of FE policy. Two decades of this have resulted in instability and, in the case of SfL, a crisis in confidence in newly established subject areas. Our suggestions focus on the key role of the funding. First, a more stable funding methodology would support continuity 
and remove the upheavals caused by year on year uncertainty. An element of 'no strings' core funding that rolls from one year to the next would enhance stability. Interestingly, three year budgets are being considered as a way of offering increased stability (Hayes, 2011). Another positive development would involve replacing unilateral, centralised changes in the cost weighting of course as a mechanism for adjusting supply with a decision-making process that involves partnership between the SFA and individual colleges.

\section{References}

Bache, I. (2003) Governing through Governance: Education Policy Control under New Labour, Political Studies, 51(2), 300-314.

Ball, S. J. (2003) The teacher's soul and the terrors of performativity. Journal of Education Policy, 18(2), 215-228.

BBC (2010) College lecturers in Birmingham go on strike, available at: http://www.bbc.co.uk/news/10362925, accessed 16.11.11.

Cohen, L., Manion, L. and Morrison, K. (2011) Research Methods in Education $-7^{\text {th }}$ Edition. London: Routledge.

Creswell, J. (2003) Research design: qualitative, quantitative, and mixed approaches (2nd ed.). Thousand Oaks, CA: Sage Publications.

Department for Business, Innovation and Skills (BIS) (2009) Skills Investment Strategy, available at: 
http://www.bis.gov.uk/assets/biscore/corporate/migratedd/publications/s/skillsinvestment-strategy.pdf; accessed: 19.07.11.

Department for Business, Innovation and Skills (BIS) (2010A) Further Education, New Horizon, Investing in Skills for Sustainable growth, available at:

http://www.bis.gov.uk/assets/biscore/further-education-skills/docs/s/10-1272-

strategy-investing-in-skills-for-sustainable-growth.pdf; accessed 18.07.11.

Department for Business, Innovation and Skills (BIS) (2010B) Skills for Sustainable

growth and Investing in Skills for Sustainable growth, Equality Impact Assessment, available at: http://www.bis.gov.uk/assets/biscore/further-education-skills/docs/s/101284-skills-for-sustainable-growth-investing-equality-impact; accessed 18.07.11

Department for Education and Employment (DfEE) (1999) The Moser Report: A Fresh Start, Chapter 5: A National Strategy and National Targets, available at:

http://www.lifelonglearning.co.uk/mosergroup: accessed 8.3.2010.

Dhillon, S., Hamilton-Victor, R., Jeens, D., Merrick, S., O'Brien, J., Siddons, N., Smith, R. and Wilkins, B. (2011) 'Skills for Life: insights from the new 'professionals", Journal of Educational Administration and History, 43(1), 61-83.

Foucault, M. (1982) The Subject and Power, Critical Inquiry, 8(4), 777-795.

Glaser, B. G., and Strauss, A. L. (1967) The Discovery of Grounded Theory: Strategies for Qualitative Research. New York: Aldine Publishing Company.

Gleeson, D., Davies, J. and Wheeler, E. (2005) On the making and taking of professionalism in the further education workplace. British Journal of Sociology of Education, 26(4), 445-460. 
Gleeson, D. and James, D. (2007) 'The paradox of professionalism in English Further Education: a TLC project perspective'. Educational Review, 59(4), 451-467.

Gorard, S. and Taylor, C. (2004) Combining Methods in Educational and Social Research. Berkshire: Open University Press.

Habermas, J. (1986) The theory of communicative action, Vol. 1. Cambridge: Polity Press.

Hamilton, M and Hillier, Y. (2006) Changing Faces of Adult Literacy, Language and Numeracy, Stoke on Trent: Trentham Books.

Hayes, J. (2011) Association of Colleges Annual Conference, available at:

http://www.bis.gov.uk/news/speeches/john-hayes-aoc-conference-speech; accessed

17.11.11.

HMSO (1992) Further and Higher Education Act, London: HMSO.

Hodgson, A., Steer, R., Spours, K., Edward, S., Coffield, F. Finlay, I. and Gregson, M. (2007) Learners in the English Learning and Skills Sector: the Implications of HalfRight Policy Assumptions, Oxford Review of Education, 33(3), 315-330.

Huddleston, P. and Unwin, L. (2007) Teaching and Learning in Further Education:

Diversity and Change, 3rd Edition. London: Routledge-Falmer.

James, D. and Biesta, G., eds. (2007) Improving learning cultures in Further Education. London: Routledge.

Keep, E. (2006) State control of the English education and training system - playing with the biggest train set in the world, Journal of Vocational Education and Training, 58(1), 47-64. 
Keep, E. (2008) From Competence and Competition to the Leitch Review, Institute for Employment Studies Working Paper, Available at: $\underline{\text { http://www.employment- }}$ studies.co.uk/pubs/report.php?id=wp17; accessed 23.11.11.

Lee, J. (2009) ‘College Success Rates Distorted’, Times Educational Supplement,

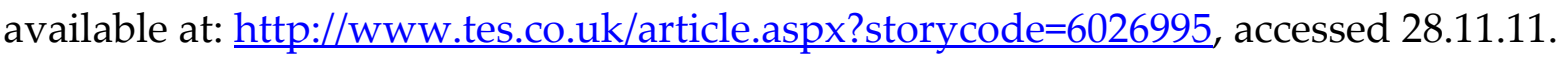

The Literacy Study Group (2010) 'The allegiance and experience of student literacy teachers in the postcompulsory education context: competing communities of practice', Journal of Education for Teaching, 36(1), 5-17.

Lo, A. W., Repin, D. V. and Steenbarger, B. N. (2005) "Fear And Greed In Financial Markets: A Clinical Study Of Day-Traders," American Economic Review, 95, 352-359.

Perryman, J. (2009) 'Inspection and the fabrication of professional and performative processes'. Journal of Education Policy, 24(5), 611-631

Programme for International Student Assessment (PISA) (2011) School Autonomy and Accountability: Are they related to students performance? PISA in Focus no. 9, available at: http://www.pisa.oecd.org/dataoecd/17/43/48910490.pdf, accessed 23.11.11.

Randle, K. and Brady, M. (1997) Managerialism and professionalism in the 'cinderella service'. Journal of Vocational Education and Training, 49(1), 121-139. Ranson, S. (1992) Towards the learning society. Educational Management and Administration, 20(2), 68-79.

Sachs, J. (2001) Teacher Professional Identity: Competing Discourses, Competing Outcomes. Journal of Educational Policy, 16(2), 149-161. 
Shain, F. and Gleeson, D. (1999) Teachers' work and Professionalism in the Post incorporated FE sector. Education and Social Justice, 1(3), 55-63.

Skills Funding Agency (2011) Annual Report and Accounts 2010-11, available at:

http://readingroom.lsc.gov.uk/sfa/SkillsFundingAgencAnnualReportAccounts2010

11 18July2011 V1.pdf; accessed 16.11.11.

Smith, R. (2007a) Work, identity and the quasi-market: the FE experience. Journal of Educational Administration and History, 39(1), 33-47.

Smith, R. (2007b) Of 'duckers and divers', mice and men: the impact of market fundamentalism in FE colleges post-incorporation, Research in Post-Compulsory Education, 12(1), 53-69

Stronach, I., Corbin, B., McNamara, O., Stark. S. and Warne. T. (2002) Towards an uncertain politics of professionalism: teacher and nurse identities in flux. Journal of Education Policy 17(1), 109-138.

University and College Union (UCU) (2009) Universities and colleges cutting education jobs in a recession, available at: http://www.ucu.org.uk/index.cfm, accessed 23.11.11. Yarrow, K. and Esland, G. (1998) The Changing Role of the Professional in the New FE, Unpublished Conference Paper, BERA Conference, Queen's University, Belfast Sage Publications. 